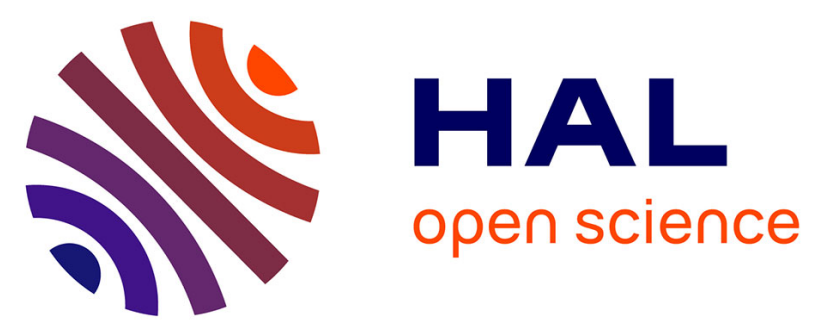

\title{
Conformational landscape of the SF6 dimer as revealed by various free jet conditions
}

M. A Gaveau, M. Mons, Laurent Bruel, A. Potapov, A. Turner, V. Boudon, P. Asselin

\section{- To cite this version:}

M. A Gaveau, M. Mons, Laurent Bruel, A. Potapov, A. Turner, et al.. Conformational landscape of the SF6 dimer as revealed by various free jet conditions. 31ST INTERNATIONAL SYMPOSIUM ON RAREFIED GAS DYNAMICS: RGD31, Jul 2018, Glasgow, France. pp.030004, 10.1063/1.5119529 . hal-02344573

\section{HAL Id: hal-02344573 \\ https://hal.science/hal-02344573}

Submitted on 4 Nov 2019

HAL is a multi-disciplinary open access archive for the deposit and dissemination of scientific research documents, whether they are published or not. The documents may come from teaching and research institutions in France or abroad, or from public or private research centers.
L'archive ouverte pluridisciplinaire HAL, est destinée au dépôt et à la diffusion de documents scientifiques de niveau recherche, publiés ou non, émanant des établissements d'enseignement et de recherche français ou étrangers, des laboratoires publics ou privés. 


\title{
Conformational landscape of the $\mathrm{SF}_{6}$ dimer as revealed by various free jet conditions
}

\author{
M.A. Gaveau ${ }^{1, \text { a) }}$, M. Mons ${ }^{1, \text { b) }}$, L. Bruel ${ }^{2, \mathrm{c})}$, A. Potapov ${ }^{3, \text { d) }}$, A.C.Turner ${ }^{4, \text { e) }}$, \\ V. Boudon ${ }^{5, \mathrm{f}}$ and P. Asselin ${ }^{6,7 \mathrm{~g})}$ \\ ${ }^{1}$ LIDYL, CEA, CNRS, Université Paris-Saclay, CEA Saclay, 91191 Gif-sur-Yvette, France \\ ${ }^{2}$ CEA Marcoule, DEN, Bagnols-sur-Cèze, France \\ ${ }^{3}$ Laboratory Astrophysics Group of the Max Planck Institute for Astronomy at the Friedrich Schiller University \\ Jena, Germany \\ ${ }^{4}$ Department of Earth and Planetary Science, University of California, Berkeley, California 94720 USA. \\ ${ }^{5}$ Laboratoire Interdisciplinaire Carnot de Bourgogne, UMR 6303 CNRS Université \\ Bourgogne Franche-Comté, 9 Av. A. Savary, BP 47870, F-21078 Dijon, France \\ ${ }^{6}$ Sorbonne Universités, UPMC Univ. Paris 06, UMR 8233, MONARIS, F-75005, Paris, France. \\ ${ }^{7}$ CNRS, UMR 8233, MONARIS, F-75005, Paris, France \\ ${ }^{a)}$ Corresponding author: marc-andre.gaveau@cea.fr \\ ${ }^{\mathrm{b}}$ michel.mons@cea.fr \\ c)laurent.bruel@cea.fr \\ d)alexey.potapov@uni-jena.de \\ e)acturner@berkeley.edu \\ f) vincent.boudon@u-bourgogne.fr \\ g) pierre.asselin@upmc.fr
}

\begin{abstract}
The experiment SPIRALES coupling a tunable infrared laser to a pulsed supersonic free jet has allowed us to reinvestigate the high-resolution absorption spectroscopy of the $\mathrm{SF}_{6}$ dimer in the $v 3$ mode region under various experimental conditions: In addition to the $\mathrm{SF}_{6}$ dimer spectrum so far reported, we demonstrate the existence of two new spectral features : i) one assigned to a second conformer of this species, characterized by a larger interatomic distance as well as ii) a complex $\left(\mathrm{SF}_{6}\right)_{2}-\mathrm{He}$.
\end{abstract}

\section{INTRODUCTION}

Supersonic free jets are an ideal way to form and study van der Waals complexes [1], through the very fast cooling and rarefaction of the gas during the expansion leading to the stabilization of these isolated species. Of course, the formation of these complexes depends dramatically on the expansion conditions, i.e. the nozzle geometry, the nature of the gas mixture and the stagnation conditions $\left(\mathrm{P}_{0}, \mathrm{~T}_{0}\right)$. Taking advantage of this sensitivity, we have used a series of different expansion conditions to explore the potential energy landscape of the $\mathrm{SF}_{6} \mathrm{dimer}$ with high resolution spectroscopy.

Low resolution spectra of the $\mathrm{SF}_{6}$ dimer were first studied by photodissociation spectroscopy in the groups of Reuss [2] and coworkers and of Scoles et al [3]. They used line-tunable cw $\mathrm{CO}_{2}$ or $\mathrm{NO}_{2}$ lasers to excite the dimers: in the first group, they monitored the depletion of the dimer while in the latter one they measured the dissociation fragments ejected off the beam axis. The absorption spectra of the dimer were not rotationally resolved and featured two broad bands respectively blue-shifted and red-shifted from the monomer band at $948 \mathrm{~cm}^{-1}$.

The first high resolution absorption spectrum of the $\mathrm{SF}_{6}$ dimer was obtained by Urban and Takami in a jet-cooled IR diode laser spectroscopy study [4]. The rotationally resolved spectrum was recorded in an axisymmetric free jet of $5 \% \mathrm{SF}_{6}$ in helium with a stagnation pressure of $7-8$ bars at a distance of $20 \mathrm{~mm}$ from the nozzle (diameter $\mathrm{D}=0.5$ $\mathrm{mm}$ ) with a rotational temperature of $1 \mathrm{~K}$. In the $\mathrm{SF}_{6}$ dimer, the triply degenerate $v_{3}$ band of the monomer splits into two bands, the parallel and perpendicular bands respectively, centered at 934.01 and $956.10 \mathrm{~cm}^{-1}$. A single 
conformer of $\left(\mathrm{SF}_{6}\right)_{2}$ was observed. The rovibrational analysis of the // band allowed to determine $v / /$, the rotational constants B'" and B' and a vibrationally averaged S-S distance equal to $475.4 \mathrm{pm}$. Only one perpendicular band was observed and found to be consistent with a $\mathrm{D}_{2 \mathrm{~d}}$ structure of the $\mathrm{SF}_{6}$ dimer. This was in agreement with the work of van Bladel et al. who predicted that the most stable $\left(\mathrm{SF}_{6}\right)_{2}$ had a $\mathrm{D}_{2 \mathrm{~d}}$ symmetry in a simple atom-atom potential model [5]. Beu and Takeuchi used a more sophisticated intermolecular potential and obtained similar conclusions [6]. However, a second predicted structure of $\mathrm{C}_{2 \mathrm{~h}}$ symmetry was not observed experimentally by Urban and Takami.

The high resolution absorption spectrum of small $\mathrm{SF}_{6}$ clusters embedded in helium droplets has also been observed in the 10 micron region [7]. It displays a partially rotationally resolved structure at the very low temperature $(0.37 \mathrm{~K})$ of the helium droplets. The perturbation due to the helium environment is weak and the shift of the solvated dimer bands with respect to those of the free dimer is expected to remain small. However, even if the rotation of the small $\mathrm{SF}_{6}$ clusters is nearly free in the helium droplet, the proximity of helium atoms leads to an increase of the moments of inertia, and therefore to a decrease of the rotational constants, which prevents determining structural information about the free dimer.

More recently, 2 or 3 conformers of the $\mathrm{SF}_{6}$ dimer have been predicted to be nearly isoenergetic within $0.5 \mathrm{~kJ} /$ mole by quantum chemistry calculations [8].

As only one conformer had been detected experimentally, the spectrum of the $\mathrm{SF}_{6}$ dimer has been reinvestigated at high resolution in the 10.5 micron region thanks to the SPIRALES setup [9].

\section{EXPERIMENTAL SETUP}

The SPIRALES experimental setup couples a tunable infrared laser and a pulsed supersonic free jet through multipass optics in order to record the absorption spectrum of rotationally cold species and weakly bound complexes that can be formed in the jet [10] [9]. The light source is a continuous wave external cavity quantum cascade laser (EC-QCL) with a spectral width of $10 \mathrm{MHz}$. It covers the $930-990 \mathrm{~cm}^{-1}$ range and its power is about $120 \mathrm{~mW}$ around $950 \mathrm{~cm}^{-1}$. It can be scanned on a frequency range of $0.8 \mathrm{~cm}^{-1}$ at a repetition rate of $100 \mathrm{~Hz}$ allowing data acquisition with a very good detectivity. $8 \%$ of the laser light is sent through two laser channels for relative and absolute frequency calibration with an accuracy around $0.0001 \mathrm{~cm}^{-1}$. The remaining light is sent through an astigmatic optical cavity aligned according to a 182-pass configuration mounted in the jet chamber (Fig. 1). The light intensity transmitted through the jet is measured by an $\mathrm{HgCdTe}$ detector in order to record the absorption spectrum.

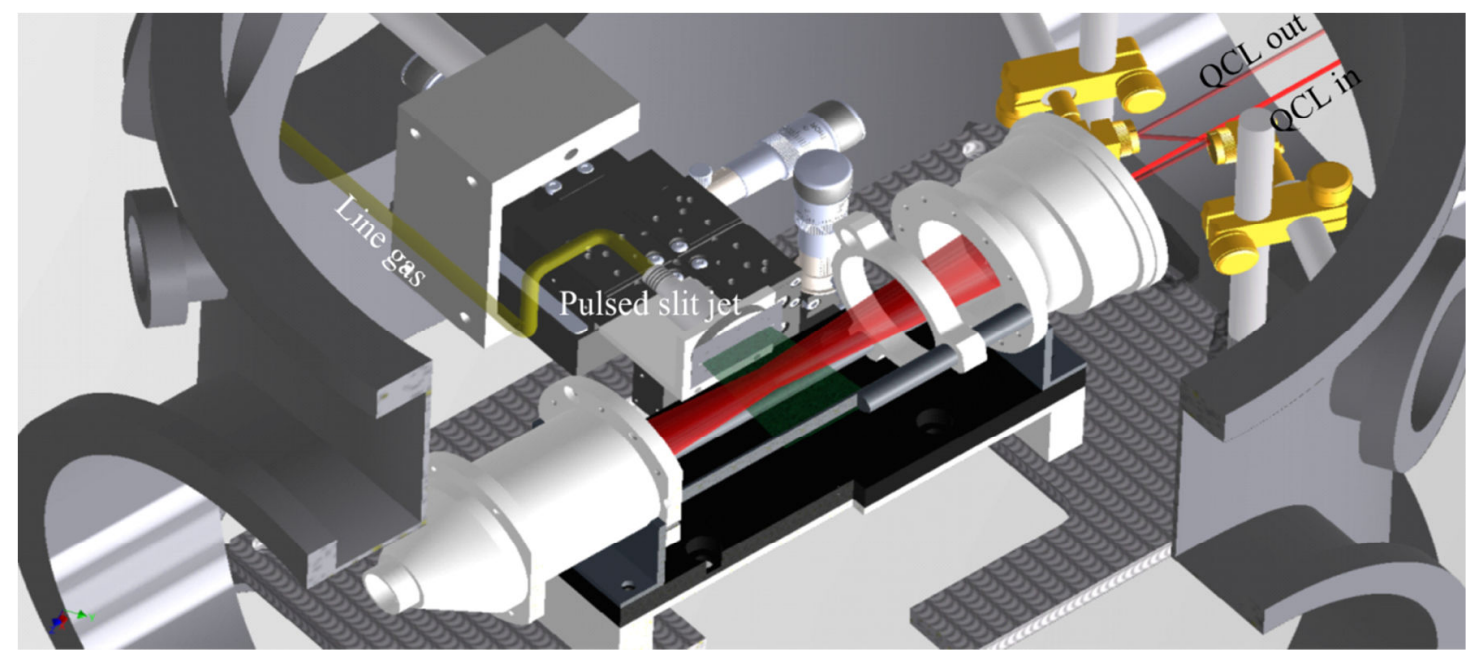

FIGURE 1. . Scheme of the multipass cell mounted in the jet chamber

The $\mathrm{SF}_{6}$ clusters were generated in pulsed supersonic expansions of $\mathrm{He} / \mathrm{SF}_{6}$ or $\mathrm{He} / \mathrm{SF}_{6} / \mathrm{Rg}$ mixtures. In order to reinvestigate the conformational landscape of $\left(\mathrm{SF}_{6}\right)_{2}$, it was necessary to change the conditions of formation and stabilization of these clusters, and therefore the conditions of the expansion. This was achieved in three different ways: 
- The supersonic free jet was generated from a pulsed nozzle (General Valve) with different geometries, either a $0.35 \mathrm{~mm}$ circular nozzle or a slit nozzle $(30 \mathrm{~mm}$ length $\mathrm{x} l=50 \mu \mathrm{m}$ width). In the latter case the expansion is slower than in the first one: rotational temperatures below $1 \mathrm{~K}$ are found at shortest distances with the axisymmetric expansion $(\mathrm{z}=12 \mathrm{~mm})$ compared to the slit expansion $(\mathrm{z}=18 \mathrm{~mm})$.

- The $\mathrm{SF}_{6}$ dilution was varied from 0.25 to $4 \%$ in $\mathrm{He}$ and also in ternary mixtures $\mathrm{He} / \mathrm{Rg} / \mathrm{SF}_{6}$.

- The stagnation pressure was varied up to 10 bars.

The absorption spectra have also been recorded at different distances from the nozzle between $\mathrm{z}=9$ and $18 \mathrm{~mm}$, in order to probe different regions of the expansion. However, the region probed with the multipass cavity is relatively broad (about $10 \mathrm{~mm}$ ) and corresponds to a large range of reduced distances $\mathrm{z} / \mathrm{D}(\mathrm{z} / \mathrm{l})$.

\section{EXPERIMENTAL RESULTS}

\section{Slit nozzle: evolution of the parallel band region of $\left(\mathrm{SF}_{6}\right)_{2}$ with the $\mathrm{SF}_{6}$ concentration and evidence for three different features in $\mathrm{He}_{-} \mathrm{SF}_{6}$ expansions}

We started our study by investigating the parallel band region of $\left(\mathrm{SF}_{6}\right)_{2}\left(933-935 \mathrm{~cm}^{-1}\right)$ in order to detect other spectroscopic signatures than the band detected by Urban and Takami [4]. Figure 2 presents the evolution of the parallel band region of the $\mathrm{SF}_{6}$ dimer as a function of the $\mathrm{SF}_{6}$ concentration (from $0.25 \%$ for (a) to $4 \%$ for (e)) in $\mathrm{He}$ for the slit expansion. The backing pressure is 6 bars, the distance from the nozzle $9 \mathrm{~mm}$.

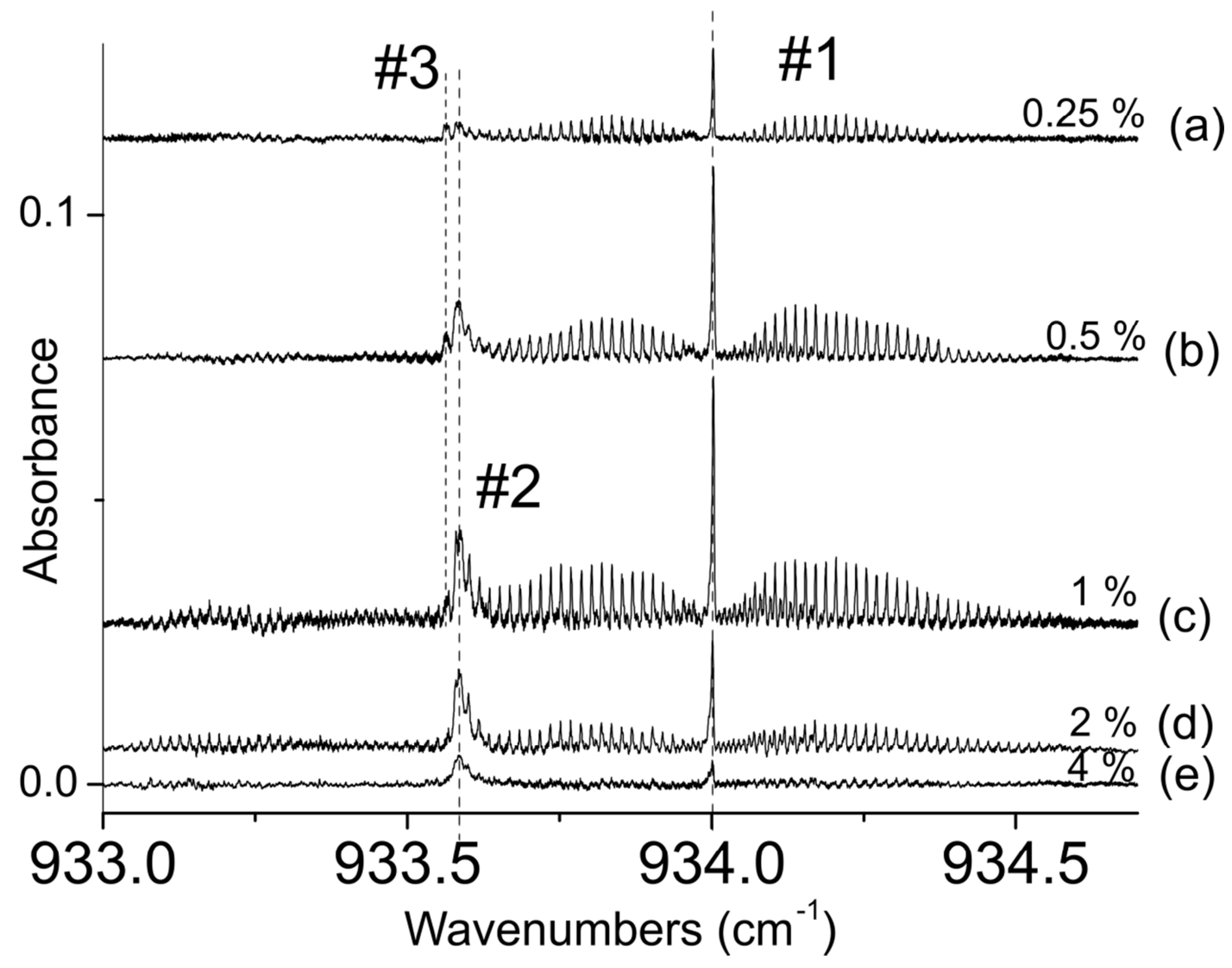

FIGURE 2. EC-QCL absorption spectra of the parallel band of $\mathrm{SF}_{6}$ dimer or various concentrations: (a) $0.25 \%$, (b) $0.5 \%$, (c) $1 \%$, (d) $2 \%$, (e) $4 \%$ of $\mathrm{SF}_{6}$ diluted in helium. The stagnation pressure is 6 bars and the axial distance from the nozzle $9 \mathrm{~mm}$. Reproduced from Phys. Chem. Chem. Phys. 19 (26), 17224 (2017) with permission from the PCCP Owner Societies. 
The band denoted \#1 is in agreement with the high resolution spectrum of Urban and Takami [4]: it is composed of a ${ }^{Q} Q(J, K)$ branch peaking at $934 \mathrm{~cm}^{-1}$ as well as well J-resolved ${ }^{Q} P(J, K)$ and ${ }^{Q} R(J, K)$ branches. The experimental linewidth $(100 \mathrm{MHz})$ does not allow resolving the $\mathrm{K}$ substructure. On the red side of band \#1, another feature is observed (noted \#2 hereafter) at $933.58 \mathrm{~cm}^{-1}$. This new spectral feature that was not detected previously presents well identified $\mathrm{P}, \mathrm{Q}$ and $\mathrm{R}$ branches. The intensities of \#1 and \#2 begin to increase with the $\mathrm{SF}_{6}$ concentration before dropping significantly above $1 \%$. However, the ratio \#2/\#1 increases continuously as the $\mathrm{SF}_{6} / \mathrm{He}$ ratio is increased: it suggests that the formation of \#2 is favored with respect to that of \#1 in these expansion conditions, i.e. with more collisions between $\mathrm{SF}_{6}$ molecules and a slightly higher translational and rotational temperature. One can notice also the presence of a small satellite band (noted \#3) on the red side of the feature \#2 at small concentration of $\mathrm{SF}_{6}$.

\section{Parallel band region of $\left(\mathrm{SF}_{6}\right)_{2}$ : comparison between slit and circular nozzle spectra}

The absorption spectrum has also been obtained with the circular nozzle free jet: It also shows the 3 spectral features detected with the slit nozzle but with very different intensities. Figure 3 presents a comparison of spectra recorded in the axisymmetric and slit expansion, with a stagnation pressure of 6 bars.

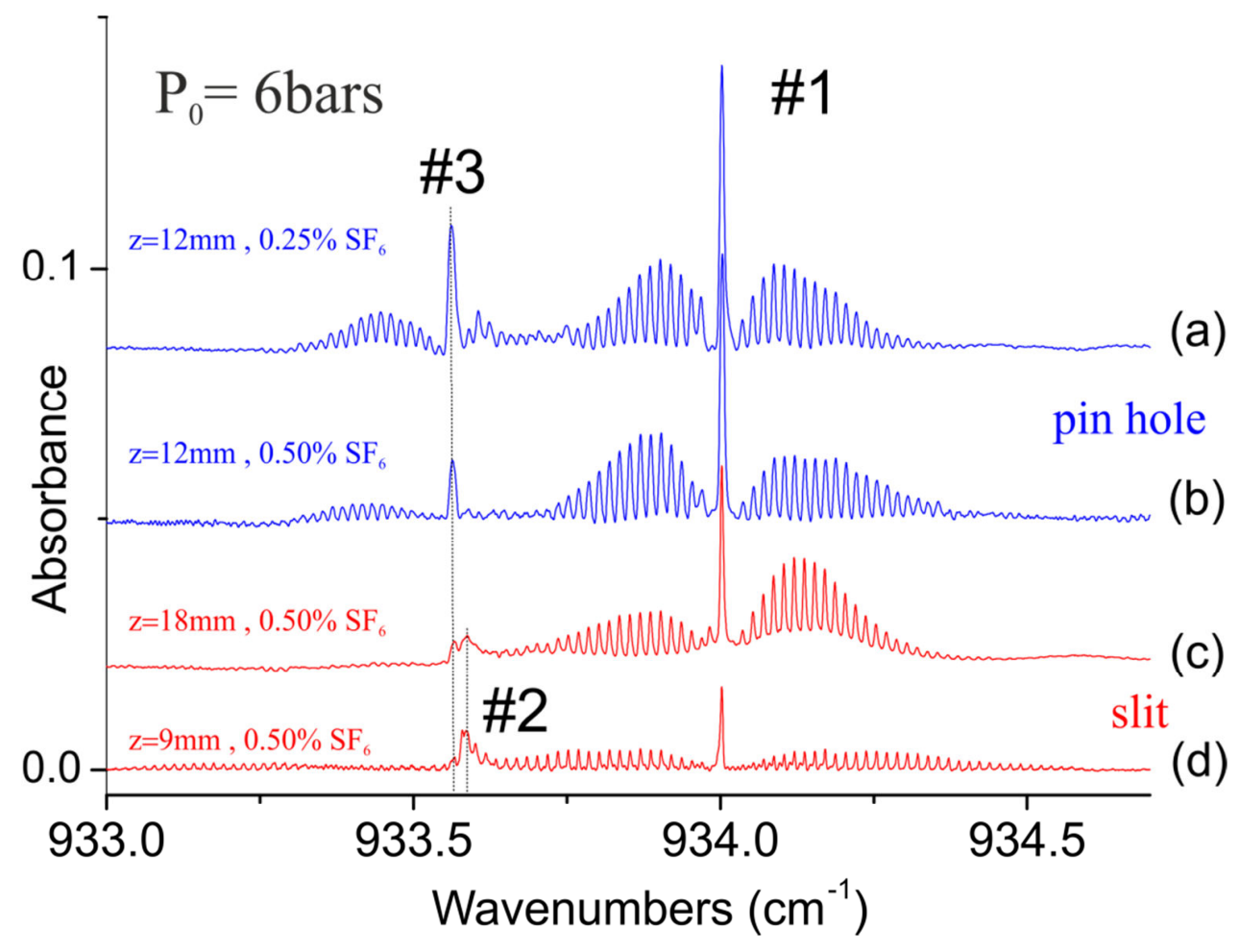

FIGURE 3. Comparison of spectra of the parallel band region of $\left(\mathrm{SF}_{6}\right)_{2}$ obtained in the pinhole expansion (in blue) and in the slit expansion with a stagnation pressure of 6 bars, at low concentration of $\mathrm{SF}_{6}$ and various distances from the nozzle exit: (a) pin hole nozzle at $\mathrm{z}=12 \mathrm{~mm}$ with $0.25 \% \mathrm{SF}_{6}$; (b) pin hole, $\mathrm{z}=12 \mathrm{~mm}, 0.5 \% \mathrm{SF}_{6}$; (c) slit nozzle, $\mathrm{z}=18 \mathrm{~mm}, 0.5 \% \mathrm{SF}_{6}$ and (d) slit nozzle, $\mathrm{z}=9 \mathrm{~mm}, 0.5 \% \mathrm{SF}_{6}$. Reproduced from Phys. Chem. Chem. Phys. 19 (26), 17224 (2017) with permission from the PCCP Owner Societies.

Figure 3 shows that the feature \#3 becomes intense in the circular nozzle free jet and at low concentrations of $\mathrm{SF}_{6}$. This band, not previously detected, is located at $933.56 \mathrm{~cm}^{-1}$ and presents $\mathrm{P}, \mathrm{Q}$ and $\mathrm{R}$ branches clearly visible in this case (Fig. 3a and b). On the contrary, the intensity of the feature \#3 becomes much smaller in the slit nozzle expansion, even if it increases a little bit at larger distances from the nozzle exit (Fig 3c). So, depending on the experimental conditions, the new spectral features (\#2 and \#3) can reach intensities that are comparable to that of the dimer feature \#1. However, it seems that \#2 and \#3 are not favoured by the same expansion conditions: \#3 appears mainly at low $\mathrm{SF}_{6}$ concentrations and low temperature expansion (circular nozzle), whereas \#2 is more intense at 
higher $\mathrm{SF}_{6}$ concentrations and higher temperature (slit expansion). Moreover, these features are very close $\left(933.58 \mathrm{~cm}^{-1}\right.$ and $933.56 \mathrm{~cm}^{-1}$ for \# 2 and \#3 respectively) and \#2 and \#3 have to be assigned while taking into account these puzzling properties.

\section{Rovibrational band contour analysis and assignments}

The conformer $\# 1$ is similar to $\left(\mathrm{SF}_{6}\right)_{2}$ previously observed by Urban and Takami [4]. The corresponding experimental spectra of the parallel and perpendicular bands are presented in red on Fig. 4 . The simulated spectra are plotted in blue assuming a $\mathrm{D}_{2 \mathrm{~d}}$ structure and a rotational temperature of $3 \mathrm{~K}$. It allows to determine the rovibrational constants and the distance S-S equal to $474.2 \mathrm{pm}$ in agreement with that previously (475 pm) measured.

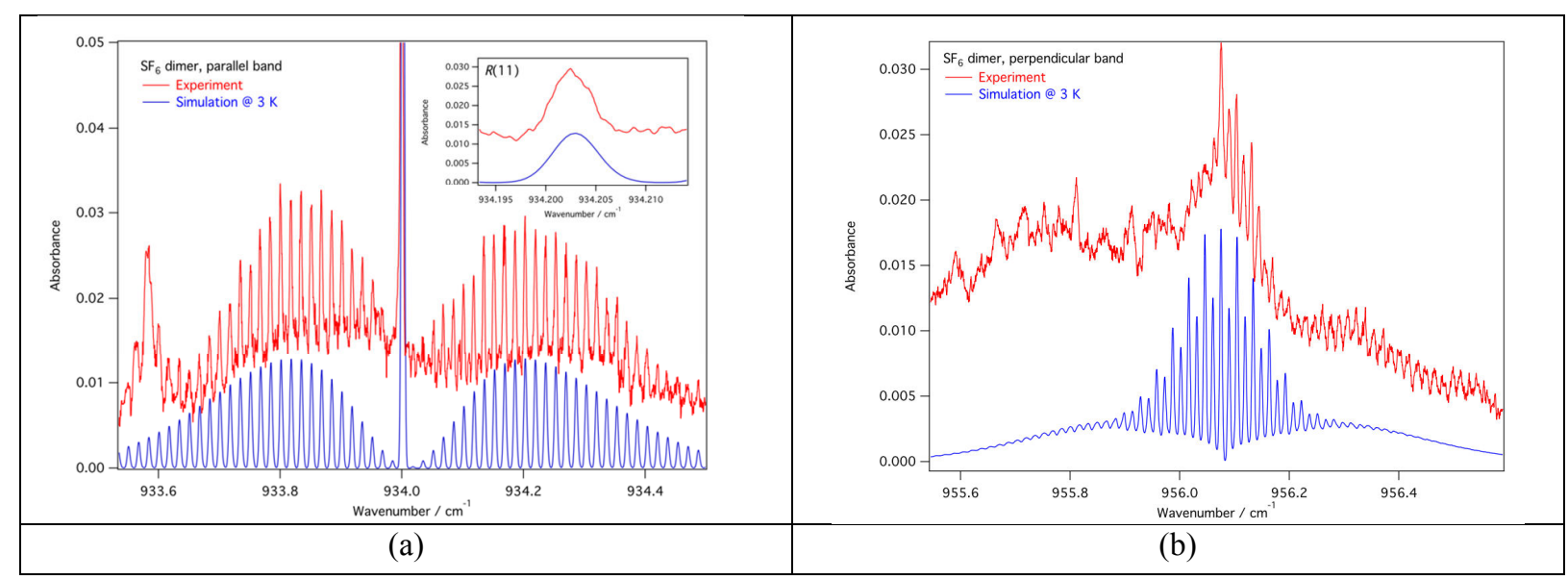

FIGURE 4. Conformer \#1: Experimental spectra (in red) of the parallel (a) and perpendicular bands (b) compared to the corresponding simulated spectra in blue

We have then to assign bands \#2 and \#3 knowing that they have maximal intensities for different experimental conditions and that the two features are very close in frequency. Several possibilities have to be considered for these assignments: Another conformer of the $\mathrm{SF}_{6}$ dimer, the $\mathrm{SF}_{6}$ trimer or larger multimer, or a complex with $\mathrm{He}_{2}$ as $\left(\mathrm{SF}_{6}\right)_{2}-$ He. Actually, the simulation shows that \#2 corresponds to a new conformer of the $\mathrm{SF}_{6}$ dimer: Figure 5 presents the comparison of the experimental spectrum recorded at $\mathrm{z}=9 \mathrm{~mm}$ in a slit nozzle expansion of $0.5 \% \mathrm{SF}_{6}$ in $\mathrm{He}\left(\mathrm{P}_{0}=6\right.$ bars), with a simulation spectrum: the latter is the sum of the simulation spectrum of the $\left(\mathrm{SF}_{6}\right)_{2}$ conformer \#1 with a symmetry $\mathrm{D}_{2 \mathrm{~d}}$ and a rotational temperature of $3 \mathrm{~K}$, and the simulation spectrum of the $\left(\mathrm{SF}_{6}\right)_{2}$ conformer $\# 2$ with a symmetry $\mathrm{C}_{2 \mathrm{~h}}$ and a rotational temperature of $8 \mathrm{~K}$. The distance $\mathrm{S}-\mathrm{S}$ in this second conformer is equal to $480.1 \mathrm{pm}$. It is interesting to note that the two rotational temperatures ( 3 and $8 \mathrm{~K}$ ) used in the simulations are substantially different: presumably because, with the multipass cell, the laser beam is able to probe several conformers present in different regions of the jet.

Concerning the band \#3, despite the contour features P, Q, R branches, some details of the contour, especially on the $\mathrm{R}$ branch side, could not be properly reproduced by a simulated symmetric top transition, suggesting that the species responsible could not be a symmetric top. The rotational constants derived being nevertheless very similar to bands 1 and 2, but inconsistent with a homotrimer molecule, we are left with an assignment to a $\left(\mathrm{SF}_{6}\right)_{2}-\mathrm{He}$ trimer. This is consistent with the fact that the presence of the He atom is not expected to strongly affect the $\mathrm{SF}_{6} \mathrm{dimer}$ features: neither the rotational constants, nor the vibrational spectral shift $\left(-0.02 \mathrm{~cm}^{-1}\right)$. A further support to this assignment has been found in complementary experiments which were performed by recording spectra at $\mathrm{z}=9 \mathrm{~mm}$ in slit nozzle expansions of ternary mixture $0.5 \% \mathrm{SF}_{6} / \mathrm{Rg} / \mathrm{He}$ and $\mathrm{Rg}=\mathrm{He}, \mathrm{Ne}, \mathrm{Ar}, \mathrm{Kr}$, Xe. Except for pure helium spectra, a $\mathrm{SF}_{6} / \mathrm{Rg}$ equimolar concentration is used. The backing pressure was $\mathrm{P}_{0}=6$ bars. These spectra are shown on Fig.6 (a). Each spectrum presents a specific spectral feature red shifted with respect to $\# 2$. The corresponding ${ }^{\mathrm{Q}} \mathrm{Q}$ branches are marked by an asterisk. The vibrational shift of these branches with respect to the central frequency of \#2 is plotted as a function of the polarizability $\alpha$ of the rare gas $\mathrm{Rg}$ : the experimental data can be perfectly fitted by a 
straight line and this linear dependence suggests that these spectral features are composed of the \#2 dimer complexed with a single rare gas atom and similar structures. The fact that the vibrational shift of feature \#3 follows this linear dependence, supports its assignment to a helium complex of the \#2 dimer. On the contrary, the \#1 dimer does not show any additional bands in its vicinity that could be assigned to a complex of the \#1 dimer complexed with a rare gas atom. This seems to indicate a specific behavior in terms of complexation.

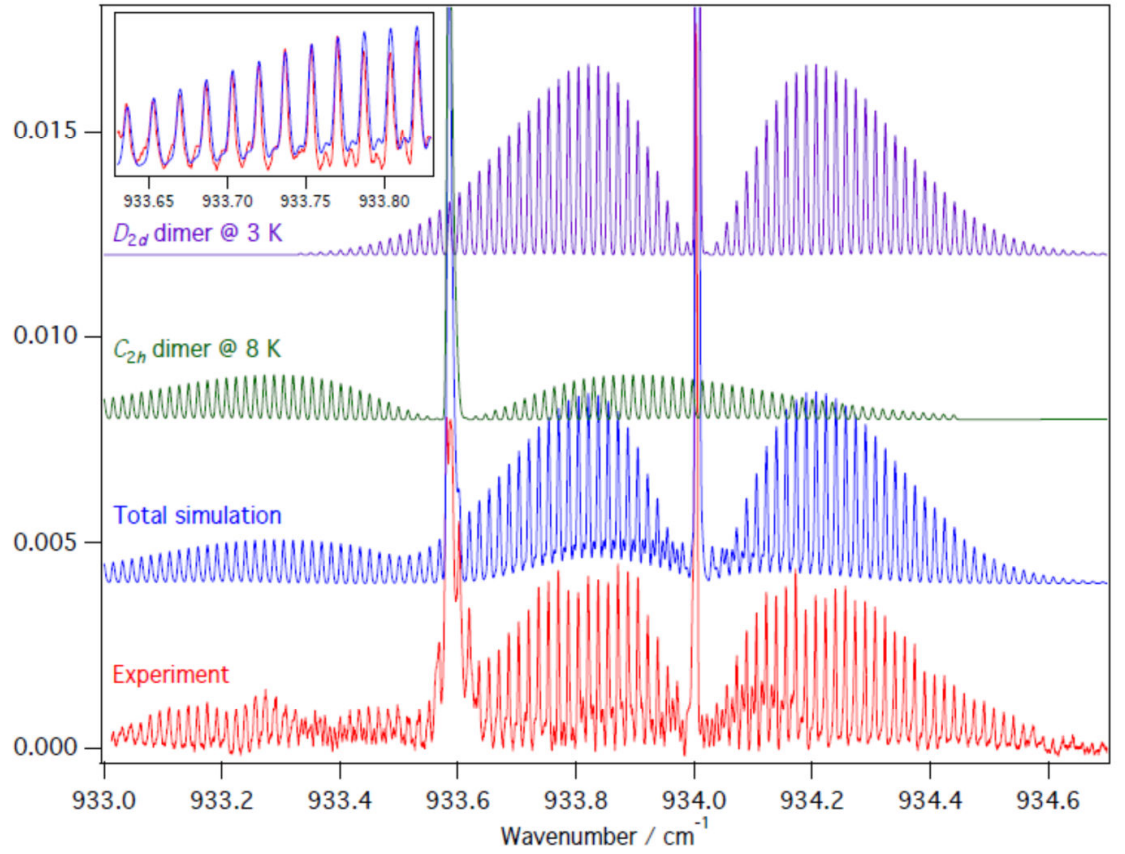

FIGURE 5. Slit nozzle spectrum (bottom in red) of the parallel band of $\left(\mathrm{SF}_{6}\right)_{2}$ recorded at $\mathrm{z}=9 \mathrm{~mm}$ with $0.5 \% \mathrm{SF}_{6}$ in 6 bar He. It is compared to the total simulation spectrum (in blue) which is the sum of the simulated spectrum of conformer \#1 $\left(\mathrm{D}_{2 \mathrm{~d}}\right.$ symmetry, $3 \mathrm{~K}$, in purple) and conformer \#2 ( $\mathrm{C}_{2 \mathrm{~h}}$ symmetry, $8 \mathrm{~K}$, in green). Reproduced from Phys. Chem. Chem. Phys. 19 (26), 17224 (2017) with permission from the PCCP Owner Societies

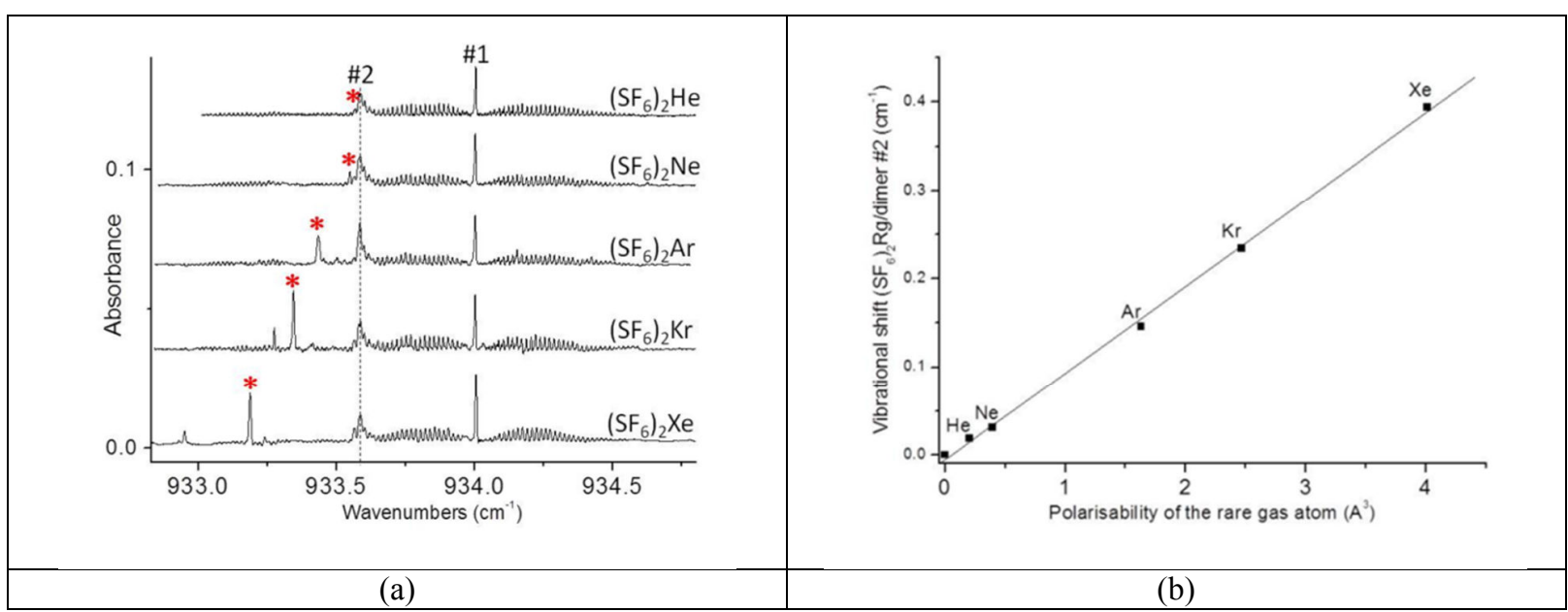

FIGURE 6. (a) Complementary spectra of the parallel band of $\left(\mathrm{SF}_{6}\right)_{2}$ recorded at $\mathrm{z}=9 \mathrm{~mm}$ in slit nozzle expansions of $0.5 \%$ $\mathrm{SF}_{6} / \mathrm{Rg} / \mathrm{He}(\mathrm{Rg}=\mathrm{He}, \mathrm{Ne}, \mathrm{Ar}, \mathrm{Kr}, \mathrm{Xe})$ with $\mathrm{P}_{0}=6$ bars. Except for the pure helium case, $\mathrm{SF}_{6} /$ and $\mathrm{Rg}$ have the same concentration. The ${ }^{\mathrm{Q}} \mathrm{Q}$ branches marked by an asterisk are assigned to $\left(\mathrm{SF}_{6}\right)_{2}-\mathrm{Rg}$ complexes. Their red shift with respect to the $\mathrm{Q}$ branch position of conformer \#2 is plotted as a function of the rare gas polarizability on panel (b). Reproduced from Phys. Chem. Chem. Phys. 19 (26), 17224 (2017) with permission from the PCCP Owner Societies 


\section{DISCUSSION AND CONCLUSION}

In this experiment, two different conformers $\# 1$ and $\# 2$ of the $\mathrm{SF}_{6}$ dimer were observed including one which had not been detected previously. The rovibrational analysis of the parallel band contours of the $v 3$ transition allows determining two distinct S-S distances for these conformers. A complex of $\mathrm{He}$ with the conformer \#2 was also identified. This was only possible thanks to the versatility of the experimental setup that enables us to vary the free jet conditions, by using either a circular nozzle or a slit nozzle, by changing the $\mathrm{SF}_{6}$ concentration of the gas mixture with $\mathrm{He}$, by varying $\mathrm{P}_{0}$ and the distance $\mathrm{z}$ from the nozzle exit where the jet was probed or by adding another rare gas to the mixture. Indeed, the dynamics of their formation seems specific to each conformer. In the circular nozzle expansion, at high pressure and low $\mathrm{SF}_{6}$ concentration, the fast cooling in the early expansion leads to the stabilization of dimer \#1 and of the heterotrimer \#3 with a low rotational temperature $(0.8 \mathrm{~K})$. As the concentration of $\mathrm{SF}_{6}$ increases, an increased number of $\mathrm{SF}_{6}-\mathrm{SF}_{6}$ collisions leads to the formation of some population of the conformer \#2.

The slit expansion is slower and the collision rates are larger at the same reduced distance $(\mathrm{z} / \mathrm{l})$ than in the circular expansion (z/D), which apparently favors the formation of the conformer \#2. There is also a conformational relaxation as proved by the decrease of the ratio between populations of \#2 and \#1 at large $\mathrm{z}$ (see Fig. $3 \mathrm{c}$ and d). This also indicates a larger stability of $\# 1$ and a low energy barrier to interconversion. The larger stability of the conformer $\# 1$ is confirmed by its presence in all the experiments where $\mathrm{SF}_{6}$ dimers are detected. As the concentration of $\mathrm{SF}_{6}$ increases, the conformer \#2 is strongly favored with respect to \#1 (Fig. 2) by $\mathrm{SF}_{6}-\mathrm{SF}_{6}$ collisions and $\mathrm{SF}_{6}$ - dimer collisions suggesting a mode of formation of \#2 significantly different from that of \#1. Population of \#2 is consistent with hot complexes formed in the early stages of the expansion by these collisions. This is also consistent with the two different rotational temperatures measured for the two conformers in the slit expansion.

A third band has been assigned to $\left(\mathrm{SF}_{6}\right)_{2}-\mathrm{He}$ trimer on the ground of complementary experiments with $\mathrm{SF}_{6}: \mathrm{Rg}: \mathrm{He}$ mixtures that has allowed the assignment of all $\left(\mathrm{SF}_{6}\right)_{2}-\mathrm{Rg}$ trimers. The hetero trimers are formed from the conformer $\# 2$. It also suggests an interconversion between \#1 and \#2 consistent with the picture of a conformer \#2 entropically favored in presence of rare gas collision partners.

\section{ACKNOWLEDGMENTS}

This work was supported by the MICHEM Labex at Sorbonne Université.

\section{REFERENCES}

1. D. H. Levy, Annu. Rev. Phys. Chem. 31, 197-225 (1980).

2. J. Geraedts, S. Setiadi, S. Stolte, and J. Reuss, Chem. Phys. Lett. 78 (2), 277-282 (1981).

3. T. E. Gough, D. G. Knight, P. A. Rowntree, and G. Scoles, J. Phys. Chem. 90 (17), 4026-4032 (1986).

4. R. D. Urban and M. Takami, J. Chem. Phys. 103 (21), 9132-9137 (1995).

5. J. W. I. van Bladel and A. van der Avoird, J. Chem. Phys. 92 (5), 2837-2847 (1990).

6. T. A. Beu and K. Takeuchi, J. Chem. Phys. 103 (15), 6394-6413 (1995).

7. M. Hartmann, R. E. Miller, J. P. Toennies, and A. F. Vilesov, Science 272 (5268), 1631-1634 (1996).

8. T. Vazhappilly, A. Marjolin, and K. D. Jordan, Journal of Physical Chemistry B 120 (8), 1788-1792 (2016).

9. P. Asselin, A. Potapov, A. C. Turner, V. Boudon, L. Bruel, M. A. Gaveau, and M. Mons, Phys. Chem. Chem. Phys. 19 (26), 17224-17232 (2017).

10. P. Asselin, Y. Berger, T. R. Huet, L. Margulès, R. Motiyenko, R. J. Hendricks, M. R. Tarbutt, S. K. Tokunaga, and B. Darquié, Physical Chemistry Chemical Physics 19 (6), 4576-4587 (2017). 